\title{
54. RADIAL VELOCITIES OF EARLY-TYPE STARS
}

\author{
J. P. KAUFMAN N
}

Technische Universität, Berlin, Germany

\begin{abstract}
With the Fehrenbach objective prism radial velocities of about 700 stars of type B0 to A0 were determined in two fields of the Southern Milky Way $\left(l^{\mathrm{II}}=295^{\circ} b^{\mathrm{II}}=-0.6^{\circ} ; l^{\mathrm{II}}=320^{\circ} b^{\mathrm{II}}=-2.5^{\circ}\right)$, with a mean error of $\pm 20 \mathrm{~km} \mathrm{~s}^{-1}$. An additional photographic $U B V$-photometry with plates of the ADH-telescope at Boyden Observatory was accomplished. Minimum distances for the stars resulted from absorption-corrected magnitudes and a MK-spectral classification. About 200 stars lay at distances greater than $1.5 \mathrm{kpc}$ from the sun. The largest distances determined were $5 \mathrm{kpc}$. From the radial velocities and distances circular velocities were derived and plotted against galactocentric distances $R$. Even within the possible error limits a positive velocity gradient showed up in the range $8 \mathrm{kpc}<R<9.5 \mathrm{kpc}$, which French authors had already found for the region $10.5 \mathrm{kpc}<R<12.5 \mathrm{kpc}$. If there do not exist significant deviations from circular motion for these stars, a conformity with Schmidt's 1965 model cannot be obtained.
\end{abstract}

